\title{
Results From the 2019 ParticipACTION Report Card on Physical Activity for Adults
}

\author{
Soultana Macridis, Christine Cameron, Jean-Philippe Chaput, Tala Chulak-Bozzer, \\ Patricia Clark, Margie H. Davenport, Guy Faulkner, Jonathon Fowles, Lucie Lévesque, \\ Michelle M. Porter, Ryan E. Rhodes, Robert Ross, Elaine Shelton, John C. Spence, \\ Leigh M. Vanderloo, and Nora Johnston
}

\begin{abstract}
Background: The ParticipACTION Report Card on Physical Activity for Adults is a knowledge exchange tool representing a synthesis of the literature and data available at the national level. The purpose of this paper is to summarize the results of the inaugural 2019 edition. Methods: Thirteen physical activity indicators, grouped into 4 categories, were graded by a committee of experts using a process that was informed by the best available evidence. Sources included national surveys, peer-reviewed literature, and gray literature such as government and nongovernment reports and online content. Results: Grades were assigned to Daily Behaviors (overall physical activity: D; daily movement: C; moderate to vigorous physical activity: F; muscle and bone strength: INC; balance: INC; sedentary behavior: INC; sleep: B-), Individual Characteristics (intentions: B+), Settings and Sources of Influence (social support: INC; workplace: INC; community and environment: B-; health and primary care settings: C-), and Strategies and Investments (government: B-). Conclusions: Generally, lower grades were given to behavior-related indicators (eg, overall physical activity) and better grades for indicators related to investments, community supports, and strategies and policies. Research gaps and future recommendations and directions are identified for each indicator to support future practice, policy, and research directions.
\end{abstract}

Keywords: advocacy, policy, health communication, adult health, knowledge translation

The many health benefits of physical activity for adults include a reduced risk for all-cause mortality and a lower risk of developing chronic conditions (eg, obesity, type 2 diabetes, hypertension, cardiovascular disease, all-cancer mortality, depression, and delays in the onset of dementia). ${ }^{1-4}$ Yet, national surveillance data demonstrate only $16 \% \%^{5}$ of adults living in Canada ( $\geq 18$ y of age) achieve Canada's Physical Activity Guidelines for Adults and Older Adults, which recommend at least 150 minute of moderate to vigorous physical activity (MVPA) per week..$^{6,7}$ In addition, the guidelines also recommend bone and muscle-strengthening activities of major muscle groups at least 2 days per week, and for older adults with poor mobility, balance-enhancing activities to prevent falls. ${ }^{6,7}$ The maintenance

Macridis and Johnston are with the Centre for Active Living, Faculty of Kinesiology, Sport, and Recreation, University of Alberta, Edmonton, AB, Canada. Cameron is with the Canadian Fitness and Lifestyle Institute, Ottawa, ON, Canada. Chaput is with the Healthy Active Living and Obesity Research Group, Children's Hospital of Eastern Ontario Research Institute, Ottawa, ON, Canada. Chulak-Bozzer and Vanderloo are with ParticipACTION, Toronto, ON, Canada. Clark and Porter are with Active Aging Canada, Shelburne, ON, Canada. Porter is also with the Centre on Aging, Faculty of Kinesiology and Recreation Management, University of Manitoba, Winnipeg, MB, Canada. Davenport and Spence are with the Faculty of Kinesiology, Sport, and Recreation, University of Alberta, Edmonton, AB, Canada. Faulkner is with the School of Kinesiology, University of British Columbia, Vancouver, BC, Canada. Fowles is with the School of Kinesiology, Acadia University, Wolfville, NS, Canada. Lévesque and Ross are with the School of Kinesiology and Health Studies, Queen's University, Kingston, ON, Canada. Rhodes is with the School of Exercise Science, Physical and Health Education, University of Victoria, BC, Canada. Shelton is with the Communities, Sport and Recreation Division, Province of Nova Scotia, Halifax, NS, Canada. Macridis (soultana@ualberta.ca) is corresponding author. of bone and muscle strength and balance through physical activity is particularly important for healthy active aging. ${ }^{8}$ With a growing older population in Canada, of which adults aged 65 years or older will represent $23 \%$ to $25 \%$ of the population by 2036 , the economic impact of inactivity is a major public health problem. ${ }^{9}$ In addition to low levels of physical activity, adults spend a large amount of their waking hours $\left(9.6 \mathrm{~h} / \mathrm{d}\right.$, excluding sleep $\left.{ }^{10}\right)$ being sedentary (ie, sitting or reclining). ${ }^{1-14}$ Although there are currently no guidelines for sedentary behavior in Canada, this behavior contributes to health risks independent of achieving physical activity recommendations. ${ }^{15}$ By getting at least $10 \%$ of those living in Canada with low levels of physical activity to move more and sit less, incidence rates of major chronic conditions would decline. From an economic standpoint, reducing physical inactivity and sedentary behavior would result in a reduction of $\$ 2.6$ billion in health care spending related to chronic conditions by 2040 , including heart disease ( $\$ 1.52$ billion), diabetes (\$842 million), and hypertension (\$202 million). ${ }^{16}$

Physical activity is influenced by an array of factors operating at the individual, social, environmental, and policy levels in the settings in which adults live, work, and recreate. ${ }^{17,18}$ To foster a better understanding of these multiple levels of influence on physical activity across the population, and to track the impact of interventions, campaigns, and policy initiatives, knowledge translation activities are needed. Knowledge translation is a "dynamic and iterative process that includes synthesis, dissemination, exchange, and ethically-sound application of knowledge" to improve the health and quality of life of a populace. ${ }^{19}$ The process can influence the direction of research and/or surveillance and monitoring, including the questions, methods, and the way in which information is obtained and interpreted within real-world 
practice, and has the potential to increase awareness, knowledge, and beliefs on issues across large populations.

ParticipACTION (www.participaction.com) is recognized as a national nonprofit organization that aims to help all living in Canada to sit less and move more. Since 1971, ParticipACTION has been delivering public education campaigns, and conducting engagement initiatives and thought leadership activities (ie, bringing experts together to provide guidance and leadership from across the country). ParticipACTION also works with its partners (sport, physical activity, and recreation organizations; government; and corporate sponsors) to prioritize physical activity for all living in Canada. ${ }^{20}$ For over 14 years, the ParticipACTION Report Card on Physical Activity for Children and Youth (initially produced by Active Healthy Kids Canada) has been an effective knowledge translation product that assesses how well Canada is doing in promoting and facilitating physical activity opportunities for children and youth. ${ }^{21}$ The Report Card on Physical Activity for Adults builds on the

\section{Table 1 Overview of the Categories, Indicators, and Grades in the 2019 ParticipACTION Report Card on Physical Activity for Adults}

\begin{tabular}{llc}
\hline Categories & Indicators & Grades \\
\hline Daily behaviors & $\begin{array}{c}\text { Overall physical activity } \\
\text { • Daily movement } \\
\text { • Moderate to vigorous } \\
\text { physical activity }\end{array}$ & D \\
& $\begin{array}{c}\text { - Bone and muscle } \\
\text { strength }\end{array}$ & INC \\
& $\begin{array}{l}\text { - Balance } \\
\text { SNC }\end{array}$ & \\
& Sedentary behavior & INC \\
& Sleep & B- \\
Individual characteristics & Intentions & B+ \\
Settings and sources of & Family and peer support & INC \\
influence & Workplace & INC \\
& Community & B- \\
& Health and primary care & C- \\
& settings & \\
Government strategies & Policies, leadership, and & B- \\
& funding & \\
\hline
\end{tabular}

documented success of the children and youth Report Card and its subsequent international adoption (Global Matrix).22,23 More specifically, ParticipACTION and its sector partners identified a need for a comprehensive understanding of adults' and older adults' physical activity levels, including multilevel influential factors and the gaps in policy, practice, and research. Synthesizing and translating this knowledge into a Report Card serves as a readily accessible resource geared to support governmental and nongovernmental organizations that work to influence physical activity policy, practice, and programming opportunities for adults living in Canada. By engaging the media, broader awareness and comprehension of the significance of the Report Card and the importance of moving more and sitting less can be delivered to the general public.

The purpose of this paper is to summarize the results of the inaugural 2019 ParticipACTION Report Card on Physical Activity for Adults (hereafter known as the Report Card). Grades were based on the best available evidence. Sources included nationallevel data including surveys, peer-reviewed literature, and gray literature, such as government and nongovernment reports. The most current data sources were considered; however, older sources were relied upon for indicators where new data were not available.

\section{Methods}

ParticipACTION led the development, communications, and dissemination of the Report Card. The Centre for Active Living (www.centre4activeliving.ca) and the Canadian Fitness and Lifestyle Institute (www.cflri.ca) were both strategic partners who played a critical role in the research and content development for the Report Card. The Report Card Research Committee (RCRC) consisted of 17 experts from across Canada who are affiliated with academic, government, and nongovernment sectors. The RCRC provided content expertise and direction to support conceptualization and grade assignment for the Report Card.

The Report Card assesses 13 indicators organized within 4 main categories including Daily Behaviors, Individual Characteristics, Settings and Sources of Influence, and Strategies and Investments (Table 1). For all indicators, objectively measured, national-level data were given highest priority and were accessed and synthesized from national-level surveillance data systems (Table 2). Where necessary, both objectively and subjectively

\section{Table 2 Data Sources for the Canadian 2019 ParticipACTION Report Card on Physical Activity for Adults}

\begin{tabular}{|c|c|c|c|c|}
\hline Survey name & $\begin{array}{c}\text { Data collection } \\
\operatorname{period}(\mathbf{s})\end{array}$ & Sample size & Age range, y & Physical activity measures \\
\hline Canadian Community Health Survey & $\begin{array}{l}2014 \\
2015 \\
2018\end{array}$ & $\sim 65,000 / y$ & $12+$ & Self-report \\
\hline Canadian Health Measures Survey & $\begin{array}{l}2009-11 \\
2014-15 \\
2016-17\end{array}$ & $\sim 9000 / y$ & $3-79$ & Accelerometer \\
\hline General Social Survey & $\begin{array}{l}2012 \\
2015\end{array}$ & $\sim 20,000$ & $15+$ & Self-report \\
\hline Municipality Survey & 2015 & １500 municipalities & - & Administrator reports \\
\hline Physical Activity Monitor & $\begin{array}{c}2006 \\
2009 \\
2014-15 \\
2016-18\end{array}$ & $\sim 7000$ & $18+$ & Self-report \\
\hline Workplace Survey & 2007-08 & $\sim 2000$ & - & Administrator report (employer) \\
\hline
\end{tabular}


Table 3 Overview of Grading Scheme

\begin{tabular}{|c|c|c|c|c|c|c|c|c|c|c|}
\hline A & & & B & & C & & D & & $\mathbf{F}$ & INC \\
\hline$A+$ & $94 \%-100 \%$ & $\mathrm{~B}+$ & $74 \%-79 \%$ & $\mathrm{C}+$ & $54 \%-59 \%$ & $\mathrm{D}+$ & $34 \%-39 \%$ & & & \\
\hline A & $87 \%-93 \%$ & $\mathrm{~B}$ & $67 \%-73 \%$ & $\mathrm{C}$ & $47 \%-53 \%$ & $\mathrm{D}$ & $27 \%-33 \%$ & $\mathrm{~F}$ & $0 \%-19 \%$ & Incomplete data \\
\hline A- & $80 \%-86 \%$ & $\mathrm{~B}-$ & $60 \%-66 \%$ & $\mathrm{C}-$ & $40 \%-46 \%$ & D- & $20 \%-26 \%$ & & & \\
\hline
\end{tabular}

measured subnational and regional data, as well as secondary data sources including recent peer-reviewed publications utilizing Statistics Canada databases, and reports such as the Canadian Longitudinal Study on Aging ${ }^{24}$ were included. National-level surveys included the Canadian Community Health Survey, ${ }^{25}$ the Canadian Health Measures Survey, ${ }^{26}$ the General Social Survey, ${ }^{27}$ the Physical Activity Monitor (PAM; Canadian Fitness and Lifestyle Research Institute [CFLRI]), ${ }^{28}$ the Workplace Survey (CFLRI), ${ }^{29}$ and the Municipality Survey (CFLRI). ${ }^{29}$ Details on each survey are in Table 2.

A summary of available data was prepared by the Centre for Active Living to facilitate the RCRC's review of the information and the grading assignment meeting held in Vancouver on May 2019. Similar to the Report Card on Physical Activity for Children and Youth, a letter grading framework was used by the RCRC to support consensus decision making (Table 3). For each indicator, data were reviewed and discussed against a predefined benchmark or optimal scenario. For individual-level behaviors, grades were based on the proportion of adults living in Canada who were meeting the benchmark(s). Grades for indicators that influence individual behaviors were based on the level of supports made available to adults living in Canada. Reflecting the focus and cover story theme of the 2019 Report Card, key considerations were factored into grading including the quality of the compiled evidence and providing data based on two adult age categories (adults [18-64 y] and older adults $[65+y])$.

\section{Results and Discussion}

The Centre for Active Living and CFLRI took the lead in the analysis and reporting of data and literature to support ParticipACTION, who led development of the Report Card and supplementary documents (ie, infographic, presentation, social media kit). Throughout the process, all materials were presented to the RCRC prior to finalization and release in October 2019. The cover story ("Better with Age: Move more today for a healthier tomorrow") is highlighted in Figure 1 and a summary of the grades is available in Table 1.

\section{Better With Age: Move More Today for a Healthier Tomorrow}

With the older adult ( $\geq 65 \mathrm{y}$ ) population in Canada expected to represent $23 \%$ to $25 \%$ of the population by $2036,{ }^{9}$ the 2019 cover story ("Better with Age: move more today for a healthier tomorrow") draws attention to the need to sit less and move more throughout the day and throughout the life course. The Report Card draws upon the latest evidence through an ecological lens to highlight life course changes to activity levels of adults living in Canada. Particular focus is on older adults and the implications of leading an inactive lifestyle including the risk of premature mortality, developing chronic conditions, declining cognitive functions, social isolation, and injuries through falls. ${ }^{1-4,30}$

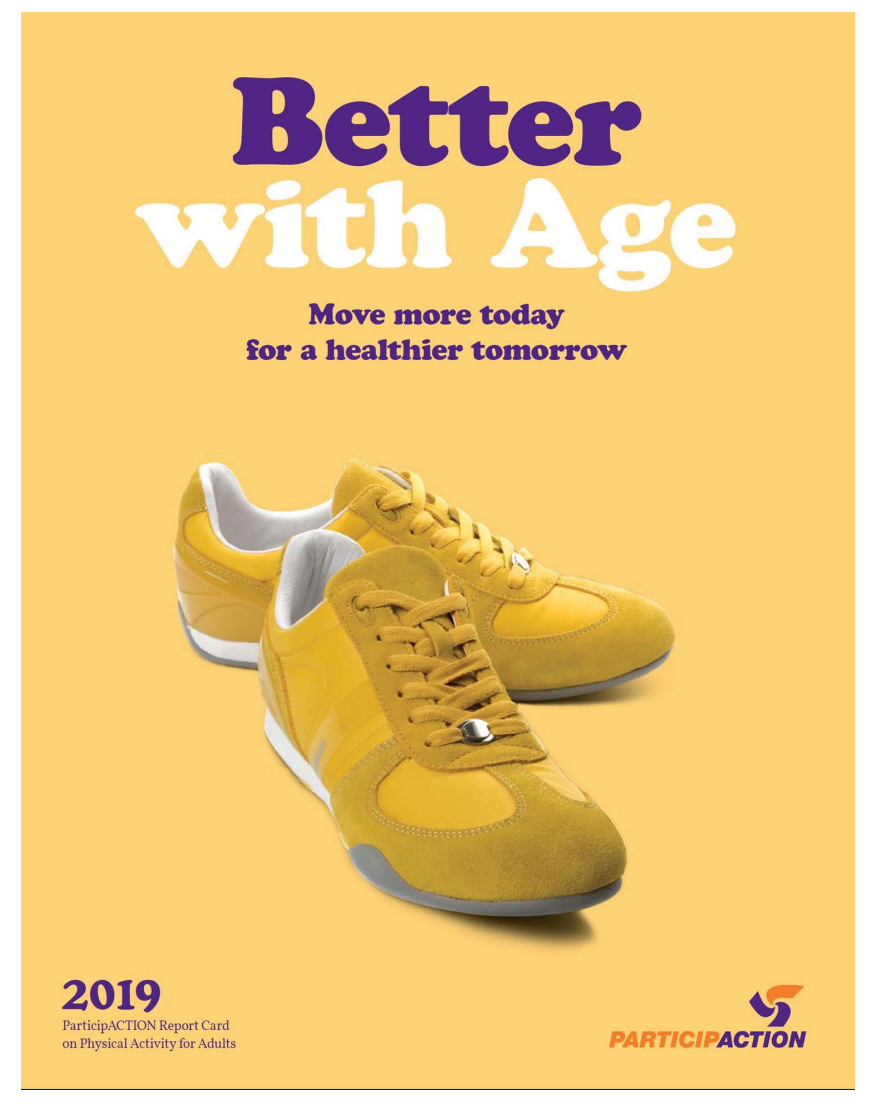

Figure 1 - Front cover of the 2019 ParticipACTION Report Card on Physical Activity for Adults.

\section{Overall Physical Activity: D}

The overall physical activity grade comprised an average of four main components that capture a daily lifestyle for activity, along with the Canada's Physical Activity Guidelines for Adults (18-64 y) and Older Adults ( $\geq 65$ y). ${ }^{6,7}$ These four components are described in the following.

\section{Daily Movements: C}

Lifestyle choices provide various opportunities to engage in light, moderate, and vigorous activities and can include active transportation, home/domestic chores, workplace activities, and active recreation (eg, cycling, dog walking, and dance). For example, women spend approximately 2.8 hours per day and men spend 1.9 hours per day on household chores to support members of the household, their property, and vehicles (General Social Survey, 2015); ${ }^{31}$ adults report spending 2.9 hours a week doing physical activities while at work, in or around their home, or while volunteering (Canadian Health Measures Survey [CHMS], 2014); ${ }^{26} 21 \%$ of adults report using active transportation, such as walking or cycling to or from work or 
school (Canadian Community Health Survey, 2014); ${ }^{25}$ and $68 \%$ of adults engaged in some form of unorganized physical activity or sport in the last 12 months (PAM, 2016-2018). ${ }^{28}$

Recent accelerometry data from the CHMS (2016-2017) ${ }^{26}$ survey highlight that $29 \%$ of adults achieve 5000 to 7499 steps per day, and $52 \% \geq 7500$ steps per day, which in a recent study, is equivalent to a "low active" and "physically active" lifestyle, respectively. ${ }^{32}$ A declining trend in steps was observed as adults living in Canada age, whereby only $30 \%$ and $33 \%$ of older adults (65-79 y) achieved low active and physically active lifestyles (CHMS, 2016-2017). ${ }^{26}$

\section{Moderate to Vigorous Physical Activity: F}

Based on accelerometer data from a nationally representative sample of adults living in Canada (CHMS, 2016-2017), only $16.4 \%$ of adults 18-79 years of age achieve the guidelines of at least $150 \mathrm{~min}$ utes of weekly MVPA in bouts of 10 minutes or more. ${ }^{5}$ A slightly lower percentage of older adults 65-79 years of age (15.2\%) achieve this recommendation compared with younger adults (16.6\%). A recently published report also examined the number of unbouted minutes per week spent in MVPA and found that $42.8 \%$ of adults living in Canada 18-79 years achieve at least 150 minutes per week. ${ }^{5}$ Therefore, MVPA was assigned an $F$ grade in alignment with the current evidence-based guidelines.

\section{Bone and Muscle Strength: INC}

Although the guidelines recommend adults of all ages engage in bone- and muscle-strengthening activities using major muscle groups at least 2 times per week, ${ }^{6,7}$ an INC was assigned as limited nationallevel data are available to support grading. Although the Canadian Longitudinal Study on Aging obtains self-reported data indicating that one in four adults living in Canada perform muscular exercises at least three times per week, these data are limited to adults 45 years or older. $^{24}$

\section{Balance: INC}

Physical activities can help maintain and improve balance over the life course, and the Canadian Longitudinal Study found that balance declines with age across age groups. As an example, for males the average balance time in a standing-balance test decreased from approximately 53 seconds among those aged 45-54 years to approximately 18 seconds in those aged 75 years and older. ${ }^{24}$ However, national-level data to support grading are limited, and thus an $I N C$ was assigned.

\section{Sedentary Behavior: INC}

Unlike the physical activity guidelines for the early years ${ }^{33}$ and for children and youth, ${ }^{34}$ no guidelines currently outline parameters of sedentary behavior for adults or older adults; resulting in a grade of $I N C$. In terms of hours, adults spend 9.6 hours per day in sedentary behavior, excluding sleep, of which 3.6 hours are spent in screentime behavior (eg, sitting or in a reclined position while watching television/videos, spending time on a computer, tablet, or other handheld electronic device). ${ }^{26}$ Once again, adults $65-79$ years spend the most hours per day sedentary $(10.1 \mathrm{~h})$, compared with adults 1834 years. Interestingly, both age groups spend the same hours per day in a seated or reclined position in front of a screen $(4.0 \mathrm{~h}) .^{26}$

\section{Sleep: B-}

Sleep behavior is recognized as an important determinant of overall health and well-being across the life span. ${ }^{35-37}$ Sleep supports many daily physical body functions including neural development, learning, memory, emotional regulation, as well as metabolic and cardiovascular health. ${ }^{38}$ Although Canada does not have specific guidelines for sleep at the moment among adults, the US-based National Sleep Foundation recommends that adults 18-64 years sleep for 7 to 9 hour a day, and adults 65 years or older sleep for 7 to 8 hours per day. ${ }^{37}$ On average, adults $18-64$ y achieve 7.1 hour per day and adults 65-79 years achieve 7.2 hours per day. ${ }^{39}$ However, the proportion of adults achieving these recommendations is $64.5 \% .{ }^{26}$ Slight declines in achievement of sleep recommendations across age groups were observed, with the greatest decline seen among adults $65-79$ years $(54.1 \%) .{ }^{26}$

\section{Intentions: $\mathbf{B +}$}

Intention, or the willingness to invest effort in a particular behavior, such as physical activity, is an important link between cognition and performing a behavior. ${ }^{40,41}$ The relationship between intention and behavior has demonstrated validity, ${ }^{42}$ with several reviews noting a positive relationship between intention and physical activity behavior. ${ }^{43-46}$ Despite positive findings, the relationship between intention and behavior is still modest, a phenomenon notoriously referred to as the "intention-behavior gap." Indeed, almost half of intenders do not follow through on their intentions to engage in physical activity. ${ }^{42,47}$ Based on the PAM Survey, $75 \%$ of adults $18-64 \mathrm{y}$ and $68 \%$ of adults $\geq 65 \mathrm{y}$ indicate a strong intention to be physically active within the next 6 months.

\section{Social Support: INC}

Social support received an INC as there are limited national-level data available to provide a full understanding of the social support individuals receive from family, peers, or other key influencing individuals to be physically active at this time. The behavior of family and friends can influence and provide support to an individual. Based on available data, adults living in Canada (18-79 y) agree to some extent that most of their family (53\%) members and some of their friends (37\%) walk for at least 30 minutes on most days of the week. However, those 18-79 years have difficulty finding others to be active with (33\%), finding places to be active (19\%), getting to and from places to be active (19\%), and finding family-oriented physical activity programs and services $(25 \%)$.

\section{Workplace: INC}

The workplace received a grade of INC as national-level data collected by CFLRI $^{29}$ in 2007-2008 was deemed outdated, and the Conference Board of Canada's Workplace survey report ${ }^{48}$ was not representative of the national landscape (approximately 200 workplaces). Workplaces can support their employees in being more active and less sedentary throughout the workday by increasing employee awareness and education, providing social support and organizational support, fostering community assets and partnerships, and developing favorable policies and programs. ${ }^{49}$

\section{Community and Environment: B-}

This indicator examined four areas in which communities can support physical activity and included: policies, strategies and plans, supports and information, programming, and facilities. Based on the CFLRI Municipality Survey, ${ }^{29}$ Canadian municipalities with at least 
1000 residents report having a formal physical activity and sport strategy $(35 \%)$ and a formal active transportation plan $(22 \%)$ to support residents to be active in their communities. Municipalities also promote physical activity resources and information, including the national guidelines (55\%), provincial/territorial guidelines $(39 \%)$, and physical literacy strategies $(28 \%)$. To coordinate programs and services, municipalities reported partnering with other organizations, with the top three being not-for-profit organizations (94\%), schools/boards (86\%), and provincial/territorial government/ agencies (75\%). Municipalities offer a variety of facilities to support physical activity, such as parks and green spaces $(93 \%)$, baseball and softball diamonds $(90 \%)$, ice rinks $(88 \%)$, soccer or football fields (84\%), and community centers/halls/shared facilities $(81 \%)$. Yet, there was a need for additional facilities and infrastructure that support physical activity opportunities including more walking/ cycling/multipurpose trails (65\%), indoor sport and recreation facilities (54\%), and outdoor sport and recreation facilities (49\%). Moreover, $40 \%$ to $60 \%$ of municipalities identified the need for repair and maintenance of various physical activity facilities.

\section{Health and Primary Care Settings: C-}

According to the 2014-2015 PAM survey, 40\% of adults have heard about physical activity from a health professional in the past 12 months. Based on these findings, health and primary care settings received a $C$ - grade. Of the $40 \%$ of adults who have heard about physical activity from a health professional, a higher percentage of adults $\geq 65$ years of age $(52 \%)$ have heard about it compared with adults $25-44$ years of age $(34 \%) .{ }^{28}$ At the same time, $23 \%$ of adults have sought advice from health care professionals on becoming more active in the past year. Among these adults, $66 \%$ felt that the advice was considerably helpful. ${ }^{28}$

\section{Strategies and Investments: B-}

Strategies and investments received a grade of $B$ - for efforts by the federal government to support physical activity through policy, leadership, and funding. In May 2018, the Federal Government released The Common Vision ${ }^{50}$ - a national policy document intended to guide the country toward ways of increasing physical activity and reducing sedentary living. The first of its kind in Canada, it takes a policy focus on physical activity and its relationship to sport, recreation, health, and other relevant policy areas. The Common Vision incorporates Indigenous perspectives, as well as input from many organizational leaders across Canada, and is meant to complement and align with other relevant Canadian policies (eg, The Canadian Sport Policy ${ }^{51}$; The Framework for Recreation in Canada: Pathways to Well-being52; and Active Canada 20/20: A Physical Activity strategy and Change Agenda for Canada-Complementary Approaches ${ }^{53}$ ). Based on criteria for key elements of a successful physical activity policy, ${ }^{54-57}$ the Common Vision has achieved the following elements: consultation with key stakeholders toward policy development; incorporation of a comprehensive policy approach inclusive of multiple agencies, strategies, and different population groups; working at different levels of government, society, and physical environment; integration of the national physical activity guideline; and recognition through branding across governments and agencies. However, it is unclear how the policy is utilized, implemented, and supported (eg, support and resources) within government, nongovernment, private sector, coalitions, and partnerships across Canada, and there is no defined time frame or accountability structure for implementation, evaluation, or surveillance of the policy to determine progress and success.

As an international leader for physical activity, Canada is committed to the WHO Global Action Plan for Physical Activity (2018-2030). ${ }^{58}$ Over the years, the Canadian Society for Exercise Physiology had developed a series of evidence-based physical activity guidelines for specific populations and conditions, including adults $(18-64 \mathrm{y}),{ }^{6}$ older adults $(65+\mathrm{y}),{ }^{7}$ pregnancy, ${ }^{59}$ multiple sclerosis, ${ }^{60}$ spinal cord injury, ${ }^{61}$ Parkinson disease, ${ }^{62}$ and hypertension. ${ }^{63}$ Most recently, the Federal Minister of Health announced more than $\$ 1.1$ million in funding to support the Canadian Society for Exercise Physiology to support development of the Canadian 24-Hour Movement Guidelines for Adults (18-64 y) and Older Adults $(65+y)$, which are anticipated for release in Fall 2020.

Recent funding has been provided by the government to support various groups, including Canadian sports organizations ( $\$ 30$ million) to enable and promote accessible, ethical, equitable, and safe sports for families, athletes, and coaches, the Canadian Association for the Advancement of Women and Sport and Physical Activity (\$3 million), ${ }^{64}$ and the New Horizons for Seniors Program (\$100 million). ${ }^{64}$ In 2018, the Government proposed to invest $\$ 47.5$ million over 5 years and $\$ 9.5$ million per year on an ongoing basis to expand the use of sport for social development in more than 300 Indigenous communities. ${ }^{65}$ Finally, in 2018, \$25 million over 5 years was committed to ParticipACTION to support the movement of improving Canada's physical activity levels. ${ }^{65}$

\section{Strengths and Limitations}

The Report Card received guidance from the RCRC, which comprised a diverse group of stakeholders with expertise in all areas of physical activity. Most notably, many RCRC members have access to national databases to support custom analyses for one or more indicators and benchmarks.

Not all indicators of this Report Card received a grade, resulting in the identification of research gaps, which, if addressed, would better inform future grades. At the individual level, little to no data were collected to support understanding of adherence to the physical activity guidelines for bone- and muscle-strengthening activities, and for balance activities among older adults. Although data were available to understand aspects of sedentary behavior, at this time, evidence-based guidelines have not been developed for adults and older adults to support grading (no benchmark for comparative purposes). Furthermore, the Report Card reveals an intention-behavior gap, where approximately three-quarters of the adult population intend to be physically active within the next 6 months, but far fewer adults actually participate. There is a need to understand the theoretical underpinnings of this gap to better assist adults living in Canada to realize their intentions to be active. ${ }^{42,66}$

Within settings and sources of influence, two indicators did not receive a grade: social support and the workplace. With respect to social support, limited data were available to understand how and what types of support individuals receive from their families and peers. Further national-level data are warranted to understand how and if adults living in Canada are supported by their close network of family and friends to be physically active.

This Report Card provided an INC grade for the Workplace. Although available national-level data were thorough, they were collected in 2007-2008 and were deemed to be outdated in relation to the current workplace context. Thus, there is a need for more national-level monitoring and surveillance to assist in understanding the current practices, programs, and policies that 
support employees to move more and sit less throughout the workday.

In relation to the highlighted topic of older adults, data collected at the national-level were limited to those living between 65 and 79 years of age. Canada's older adult population is growing and is living longer than previous generations, and there is a need for national-level surveillance systems to increase their age cutoff point to ensure all older adults are fully represented. Finally, the 2019 Report Card represents a targeted and purposeful synthesis of national-level literature and data. Data on national-level disparities were considered only for certain indicators, where available.

\section{Conclusion}

The Report Card points toward areas for improvements and where more work is required within policy, practice, and research that can support improvements in physical activity for adults. Future report cards will document any progress toward these goals. The proportion of adults living in Canada that meet physical activity guidelines is low. Although the Canadian government has made modest investments in physical activity policies, leadership, and funding to support adults to move more and sit less, such investments have not resulted in an active population. Overall, in order to see a change in the physical activity levels of adults living in Canada, there is a need to better understand and develop strategic approaches that cross multiple categories of influence outlined in this Report Card.

\section{Acknowledgments}

The authors would like to acknowledge the teams from ParticipACTION, the Centre for Active Living, and the Canadian Fitness and Lifestyle Institute for undertaking the development of the Report Card. Production of the 2019 ParticipACTION Report Card on Physical Activity for Adults was made possible through funding from the Public Health Agency of Canada and Sport Canada. Conflicts of Interest: L.M.V. and T.C.B. are employees of ParticipACTION.

\section{References}

1. Warburton DER, Bredin SSD. Health benefits of physical activity: a systematic review of current systematic reviews. Curr Opin Cardiol. 2017;32(5):541-556. PubMed ID: 28708630 doi:10.1097/HCO. 0000000000000437

2. Paterson DH, Warburton, D.E. Physical activity and functional limitations in older adults: a systematic review related to Canada's physical activity guidelines. Int J Behav Nutr Phys Act. 2010;7(1):38. PubMed ID: 20459782 doi:10.1186/1479-5868-7-38

3. Mammen G, Faulkner G. Physical activity and the prevention of depression: a systematic review of prospective studies. Am J Prev Med. 2013;45(5):649-657. PubMed ID: 24139780 doi:10.1016/j. amepre.2013.08.001

4. Swift DL, McGee JE, Earnest CP, Carlisle E, Nygard M, Johannsen NM. The effects of exercise and physical activity on weight loss and maintenance. Prog Cardiovasc Dis. 2018;61(2):206-213. PubMed ID: 30003901 doi:10.1016/j.pcad.2018.07.014

5. Clarke J, Colley R, Jannssen I, Tremblay MS. Accelerometermeasured moderate-to-vigorous physical activity of Canadian adults, 2007 to 2017. Health Rep. 2019;30(8):3-10. PubMed ID: 31454407
6. Canadian Society for Exercise Physiology. Canadian physical activity guidelines for adults 18 to 64 years. 2011. https://csepguidelines.ca/ adults-18-64/.

7. Canadian Society for Exercise Physiology. Canadian physical activity guidelines for adults 65+ years. 2011. https://csepguidelines.ca/ adults-65/.

8. Bauman A, Merom D, Bull FC, Buchner DM, Fiatarone Singh MA. Updating the evidence for physical activity: summative reviews of the epidemiological evidence, prevalence, and interventions to promote “active aging." Gerontologist. 2016;56(suppl):S268-S280. doi:10. 1093/geront/gnw031

9. Public Health Agency of Canada. Population projections for Canada, provinces and territories. 2015. https://www150.statcan. gc.ca/n1/pub/91-520-x/2010001/aftertoc-aprestdm1-eng.htm. Accessed September 23, 2019.

10. Centre for Surveillance and Applied Research. Physical Activity, Sedentary Behaviour and Sleep (PASS) indicators data tool. Public Health Infobase. 2018. https://health-infobase.canada.ca/pass/datatool?index=1036. Accessed August 15, 2019.

11. Rhodes RE, Mark RS, Temmel CP. Adult sedentary behavior. Am J Prev Med. 2012;42(3):e3-e28. PubMed ID: 22341176 doi:10.1016/j. amepre.2011.10.020

12. de Rezende LFM, Rey-López JP, Matsudo VKR, do Carmo Luiz O. Sedentary behavior and health outcomes among older adults: a systematic review. BMC Public Health. 2014;14(1):333. doi:10. 1186/1471-2458-14-333

13. Pate RR, O'Neill JR, Lobelo F. The evolving definition of "sedentary”. Exerc Sport Sci Rev. 2008;36(4):173-178. PubMed ID: 18815485 doi:10.1097/JES.0b013e3181877d1a

14. Sedentary Behaviour Research Network. Letter to the Editor: Standardized use of the terms "sedentary" and "sedentary behaviours." Appl Physiol Nutr Metab. 2012;37(3):540-542. doi:10.1139/h2012-024

15. Ekelund U, Tarp J, Steene-Johannessen J, et al. Dose-response associations between accelerometry measured physical activity and sedentary time and all cause mortality: systematic review and harmonised meta-analysis. BMJ. 2019;366:14570. PubMed ID: 31434697 doi: $10.1136 / \mathrm{bmj} .14570$

16. Fares B, Dinh T, Thériault L. Moving Ahead: The Economic Impact of Reducing Physical Inactivity and Sedentary Behaviour. Ottawa, ON: The Conference Board of Canada; 2014.

17. Spence JC, Lee RE. Toward a comprehensive model of physical activity. Psychol Sport Exerc. 2003;4(1):7-24. doi:10.1016/S14690292(02)00014-6

18. Rhodes RE, Janssen I, Bredin SSD, Warburton DER, Bauman A. Physical activity: Health impact, prevalence, correlates and interventions. Psychol Health. 2017;32(8):942-975. PubMed ID: 28554222 doi:10.1080/08870446.2017.1325486

19. Canadian Institutes of Health Research. Knowledge translation: definition. 2018. http://www.cihr-irsc.gc.ca/e/29529.html. Accessed August 12, 2019.

20. Latimer-Cheung A, Murumets K, Faulkner G. ParticipACTION: The national voice of physical activity and sport participation in Canada. In: Pate R\& Buchner D, eds. Implementing Physical Activity Strategies. Champaign, IL: Human Kinetics; 2014:61-70.

21. Colley RC, Brownrigg M, Tremblay MS. A model of knowledge translation in health the active healthy kids Canada report card on physical activity for children and youth. Health Promot Pract. 2012;13(3):320-330. PubMed ID: 22447666 doi:10.1177/ 1524839911432929

22. Tremblay MS, Barnes JD, Cowie Bonne J. Impact of the active healthy kids Canada report card: a 10-year analysis. J Phys Act Health. 2014;11(suppl):S3-S20. doi:10.1123/jpah.2014-0167 
23. Tremblay MS, Barnes JD, Gonzalez SA, et al. Global Matrix 2.0: Report card grades on the physical activity of children and youth comparing 38 countries. J Phys Act Health. 2016;13(s2):S343-S366. doi:10.1123/jpah.2016-0594

24. Raina P, Wolfson C, Kirkland S, Griffith L. The Canadian longitudinal study on aging report on health and aging in Canada: Findings from baseline data collection 2010-2015. 2018. https://www.clsaelcv.ca/stay-informed/new-clsa/2018/canadian-longitudinal-studyaging-releases-first-report-health-and-aging. Accessed May 2, 2019.

25. Statistics Canada. Canadian Community Health Survey. 2018. http:// www23.statcan.gc.ca/imdb/p2SV.pl?Function=getSurvey\&SDDS= 3226. Accessed July 24, 2019.

26. Statistics Canada. Canadian Health Measures Survey (CHMS). 2019. https://www.statcan.gc.ca/eng/survey/household/5071. Accessed July 24, 2019.

27. Statistics Canada. The general social survey: an overview. 2017. https://www150.statcan.gc.ca/n1/pub/89f0115x/89f0115x2013001eng.htm. Accessed July 24, 2019.

28. Canadian Fitness and Lifestyle Research Institute. Physical activity monitor survey. 2019. https://www.cflri.ca/category/2016-2018physical-activity-monitor.

29. Canadian Fitness and Lifestyle Research Institute. Survey of settings. 2019. https://www.cflri.ca/survey-settings.

30. Kraus WE, Powell KE, Haskell WL, et al. Physical activity, all-cause and cardiovascular mortality, and cardiovascular disease. Med Sci Sports Exerc. 2019;51(6):1270-1281. PubMed ID: 31095084 doi:10. 1249/MSS.0000000000001939

31. Moyser M, Burlock A. Time Use: Total Work Burden, Unpaid Work, and Leisure. Statistics Canada; 2018:30.

32. Tudor-Locke C, Craig CL, Thyfault JP, Spence JC. A step-defined sedentary lifestyle index: $<5000$ steps/day. Appl Physiol Nutr Metab. 2013;38(2):100-114. PubMed ID: 23438219 doi:10.1139/apnm2012-0235

33. Canadian Society for Exercise Physiology. Canadian 24-hour movement guidelines for the early years: An integration of physical activity, sedentary behaviour, and sleep. Canadian Society for Exercise Physiology; 2017. http://csepguidelines.ca/early-years-0-4/. Accessed November 2018.

34. Tremblay MS, Carson V, Chaput JP, et al. Canadian 24-hour movement guidelines for children and youth: an integration of physical activity, sedentary behaviour, and sleep. Appl Physiol Nutr Metab. 2016;41(6):S311-S327. doi:10.1139/apnm-2016-0151

35. Canadian Sleep Society. Normal sleep-patient information brochure. 2018. https://css-scs.ca/resources/brochures/normal-sleep. Accessed September 19, 2018.

36. Office of Disease Prevention and Health Promotion. Sleep health. 2017. https://www.healthypeople.gov/2020/topics-objectives/topic/ sleep-health. Accessed September 19, 2018.

37. Hirshkowitz M, Whiton K, Albert SM, et al. National Sleep Foundation's updated sleep duration recommendations: final report. Sleep Health. 2015;1(4):233-243. PubMed ID: 29073398 doi:10.1016/j. sleh.2015.10.004

38. Mukherjee S, Patel SR, Kales SN, et al. An official American Thoracic Society statement: the importance of healthy sleep. Recommendations and future priorities. Am J Respir Crit Care Med. 2015;191(12):1450-1458. PubMed ID: 26075423 doi:10.1164/rccm. 201504-0767ST

39. Chaput JP, Wong SL, Michaud I. Duration and quality of sleep among Canadians aged 18 to 79. Health Rep. 2017;28:28-33. PubMed ID: 28930365

40. Rhodes RE, Rebar AL. Conceptualizing and defining the intention construct for future physical activity research. Exerc Sport Sci Rev.
2017;45(4):209-216. PubMed ID: 28704222 doi:10.1249/JES. 0000000000000127

41. Sheeran P. Intention-Behavior relations: a conceptual and empirical review. Eur Rev Soc Psychol. 2002;12(1):1-36. doi:10.1080/ 14792772143000003

42. Rhodes RE, Yao CA. Models accounting for intention-behavior discordance in the physical activity domain: a user's guide, content overview, and review of current evidence. Int J Behav Nutr Phys Act. 2015;12(1):9. doi:10.1186/s12966-015-0168-6

43. Amireault S, Godin G, Vézina-Im LA. Determinants of physical activity maintenance: a systematic review and meta-analyses. Health Psychol Rev 2013;7(1):55-91. doi:10.1080/17437199.2012. 701060

44. Rhodes RE, Quinlan A. Predictors of physical activity change among adults using observational designs. Sports Med. 2015; 45(3):423-441. PubMed ID: 25312706 doi:10.1007/s40279-0140275-6

45. Choi J, Lee M, Lee JK, Kang D, Choi JY. Correlates associated with participation in physical activity among adults: a systematic review of reviews and update. BMC Public Health. 2017;17(1):356. PubMed ID: 28438146 doi:10.1186/s12889-017-4255-2

46. Rhodes RE, Lubans DR, Karunamuni N, Kennedy S, Plotnikoff R. Factors associated with participation in resistance training: a systematic review. Br J Sports Med. 2017;51(20):1466-1472. PubMed ID: 28404558 doi:10.1136/bjsports-2016-096950

47. Rhodes RE, de Bruijn GJ. How big is the physical activity intentionbehaviour gap? A meta-analysis using the action control framework. Br J Health Psychol. 2013;18(2):296-309. PubMed ID: 23480428 doi:10.1111/bjhp.12032

48. Conference Board of Canada. Moving ahead: workplace interventions to reduce physical inactivity and sedentary behaviour. 2015 . http://www.conferenceboard.ca/e-library/abstract.aspx?did=7544.

49. Alberta Health Services, \& Centre for Active Living. Active Workplace Audit Toolkit. Edmonton, AB: Centre for Active Living; 2019.

50. Public Health Agency of Canada. Let's Get Moving: A Common Vision for Increasing Physical Activity and Reducing Sedentary Living in Canada. Public Health Agency of Canada: Ottawa, ON; 2018.

51. SIRC Sport Research. Canadian sport policy. 2012. https://sirc. ca/resources/csp/canadian-sport-policy-2012. Accessed April 24, 2019.

52. Canadian Parks and Recreation Association/Interprovincial Sport and Recreation Council. A Framework for Recreation in Canada2015-Pathways to Wellbeing. Canadian Parks and Recreation Association: Ottawa, ON; 2015.

53. Spence JC, Faulkner G, Costas Bradstreet C, Duggan M, Tremblay MS. Active Canada 20/20: a physical activity plan for Canada. Can J Public Health. 2016;106(8):e470-e473. PubMed ID: 26986905 doi:10.17269/CJPH.106.5041

54. Shephard RJ, Lankenau B, Pratt M, et al. Physical activity policy development: a synopsis of the WHO/CDC consultation, September 29 through October 2, 2002, Atlanta, Georgia. Public Health Rep. 2004;119(3):346-351. PubMed ID: 15158113 doi:10.1016/j.phr. 2004.04.013

55. World Health Organisation. Global Strategy on Diet, Physical Activity and Health = The World Health Organization. A Global Strategy for Diet, Physical Activity, and Health. Geneva, Switzerland: World Health Organisation; 2004.

56. World Health Organisation. Diet, nutrition and the prevention of chronic diseases. Report of a joint WHO/FAO expert consultation. Geneva, Switzerland: World Health Organisation; 2003. 
57. Schoeppe S, Bauman A, Bull F. International Review of National Physical Activity Policy. University of Sydney; 2004.

58. World Health Organisation. Global Action Plan on Physical Activity 2018-2030: More Active People for a Healthier World. Geneva, Switzerland: World Health Organization; 2018. Licence: CC BY-NCSA 3.0 IGO.

59. Canadian Society for Exercise Physiology. 2019 Canadian physical activity guideline for physical activity throughout pregnancy. 2019. https://csepguidelines.ca/guidelines-for-pregnancy/.

60. Canadian Society for Exercise Physiology. Canadian physical activity guidelines for adults with multiple sclerosis. 2011. https:// csepguidelines.ca/wp-content/uploads/2018/10/CSEP_MS_PAGuide lines_adults_en.pdf.

61. Canadian Society for Exercise Physiology. Canadian physical activity guidelines for adults with spinal cord injury. 2011. https://
www.csep.ca/CMFiles/Guidelines/specialpops/SCIPAGuidelinesClient. pdf.

62. Parkinson Society Canada. Physical activity and parkinson's disease. 2012. https://www.csep.ca/CMFiles/Guidelines/specialpops/ PSC_Physical_Activity_resource_and_chart_final\%20English\% 20march2012.pdf.

63. Hypertension Canada. Hypertension Canada Guidelines. 2015. https://guidelines.hypertension.ca/.

64. Government of Canada. Budget 2019: Table of Contents. Ottawa, ON: Government of Canada; 2019.

65. Government of Canada. Budget 2018: Table of Contents. Ottawa, ON: Government of Canada; 2018.

66. Sheeran P, Webb TL. The intention-behavior gap. Soc Personal Psychol Compass. 2016;10(9):503-518. doi:10.1111/spc3. 12265 